\title{
The effect of Dicer knockout on RNA interference using various Dicer substrate interfering RNA structures
}

\author{
Min-Sun Song ${ }^{1}$ and John J Rossi ${ }^{1,2}$ * \\ ${ }^{1}$ Department of Molecular and Cellular Biology, Beckman Research Institute of City of Hope, City of \\ Hope, Duarte, CA 91010, USA \\ ${ }^{2}$ Irell and Manella Graduate School of Biological Sciences, Beckman Research Institute of City of \\ Hope, City of Hope, Duarte, CA 91010, USA \\ *Corresponding author: John J. Rossi, \\ Email address: jrossi@coh.org. \\ Running title: Dicer regulation of DsiRNAs
}

Keywords: Dicer, tetra-loop, Dicer-substrate siRNA(DsiRNA), RNA interference(RNAi), RNA biogenesis, Dicer knockout 


\begin{abstract}
Dicer-substrate siRNA (DsiRNA) was a useful tool for sequence-specific gene silencing. DsiRNA was proposed to have increased efficacy via RNAi gene silencing, but the molecular mechanism underlying the increased efficacy is not precise. We designed the tetra-looped DsiRNA as the tetra-looped RNAs have been reported more stable structure and increased binding efficiency with RNA and protein. To gain a deeper understanding of the Dicer function of DsiRNA, we knocked out Dicer in the HCT116 cell line and analyzed the efficacy of various Dicer substrates on RNAi gene silencing activity. Tetra-looped DsiRNA demonstrated increased efficacy of gene silencing Dicer expressing cells with activity favoring the guide strand. The gene silencing activity of all DsiRNAs was reduced in Dicer knockout cells. Thus, this study allows us to understand the Dicer function of key RNAi silencing and provides valuable resources for RNAi research and applications.
\end{abstract}




\section{Introduction}

A hairpin structure is one of the most abundant RNA secondary structural elements. RNA hairpins play essential structural and functional roles by providing sites for RNA tertiary contacts and protein binding, which facilitates the assembly of ribonucleoprotein particles. More than half of all known RNA hairpins are composed of four nucleotides, called tetra-loops (1-5). Consequently, RNA tetra-loops are predominant and are commonly found in nature. Tetra-loops have been found in many RNAs, including ribosomal RNA (rRNA), mRNA, a group I intron ribozyme, RNase III, coxsackievirus B3, and heron Hepatitis B virus (6-10). In general, RNA tetra-loops are more stable compared to smaller or larger loops accommodating the same stem, because the compact structures of tetraloops impact them with high thermal stability and nuclease resistance.These loops involve base stacking, base-phosphate, and base-ribose hydrogen bonds (11). GNRA and UNCG (5' to 3', N: any base and R: purine) are the most common among the known stable tetraloops $(12,13)$. Among these families, a GAAA tetra-loop has a U-turn motif, which can be involved in RNA activity by facilitating both RNA-RNA and RNA-protein interactions (14). It is noteworthy that RNA tetra-loops confer functional roles within the RNA beyond allowing secondary structure formation. The tetra-loops generally participate in RNA tertiary interactions with other RNAs and RNA-protein interactions $(11,15)$.

Previously, chemically synthesized 25- to 27-nucleotide (nt)-long double-stranded RNAs (dsRNAs) with 2-nt 3' overhangs were identified as substrates for the Dicer endoribonuclease. These Dicer-substrate siRNAs (DsiRNAs) are recognized and processed into shorter small interfering 21-22bp RNAs (siRNAs) by endogenous Dicer when they are introduced into mammalian cells (16). The interaction between DsiRNAs and Dicer promotes the loading of siRNAs into the RNA-induced silencing complex (RISC) with strand-specific orientation, and the association of the guide strand into the argonaute protein Ago2 in the cytoplasm (16-18) Subsequently DsiRNAs have been reported to be up to 10-fold more potent in silencing a targeted gene than canonical 21-nt siRNAs (19-21). In contrast, endogenous microRNA (miRNA) is processed from hairpin-containing primary transcripts (pri-miRNA) of nuclear hairpin double-strand RNA 
into pre-miRNA by the ribonuclease Drosha, before it is transported to the cytoplasm and further cleaved by Dicer (22). RNA containing hairpin structures influences Dicer's activity and site selection (23). The loop structure of short hairpin RNAs (shRNAs), which are artificially designed small RNAs, contributes to the biogenesis and subsequent activity of siRNA with Dicer (24). How can the activity of small RNAs be improved act by Dicer? We may find the answer to this in the study of structures between Dicer and small RNAs. A cryo-electron microscopy structure study showed that the terminal loop of pre-miRNA interacts with the N-terminal DEAD-like helicases domain $(\mathrm{DExD}) / \mathrm{H}$-box helicase domain of Dicer and its co-factor, transactivation response element RNA-binding protein (TRBP) (25). This implies that the presence of loops within small RNAs may influence not only Dicer cleavage activity but also gene silencing efficacy.

In this study, we designed various DsiRNAs with or without a 5'-GAAA-3' tetra-loop. To determine whether the multiple versions of DsiRNAs affected Dicer-dependent gene silencing efficacy, we generated Dicer knockout cells (named H2-2) in the colorectal cancer cell line HCT116. We compared the gene silencing activity of the various DsiRNAs in wild-type (WT) HCT116 and Dicer-inactivated H2-2 cells. Compared to WT cells, the gene silencing activity of DsiRNAs, including both original and tetralooped versions, was reduced 2- fold to 37- fold in H2-2 cells. At present, it is not clear whether Dicer can directly affect the RNA interference (RNAi) activity of DsiRNAs. These results have important ramifications for the role of Dicer in the efficacy of DsiRNAs and tetra-looped DsiRNA biogenesis. 


\section{Results}

\section{Design of DsiRNAs targeting hnRNPH1}

We previously observed successful gene silencing activity using DsiRNAs that targeted the RNA binding protein heterogeneous nuclear ribonucleoprotein $\mathrm{H}$ (hnRNPH1); this activity was associated with Ago2, TRBP, and Dicer $(17,26)$. In the present study, we synthesized DsiRNAs specific to hnRNPH1 that also contained various tetra-loop and stem structures (Figure 1; Table 1). DsiRNAs that enhanced the efficiency of Dicer-mediated loading of siRNA into the RISC were designed as asymmetric duplexes containing a 27-base antisense strand with a 2-nt 3'-overhang and a 25-nt sense strand. Two DNA nucleotides were included at the 3' end of the sense strand to create a blunt end (27). These asymmetric 25/27-mer siRNAs were optimized for processing by Dicer. We designed two versions of the DsiRNA (DsiRNA I [DI] and DsiRNA II [DII]), which differed by only a single base pair. Previously, our results showed that hnRNPH1-targeted DsiRNAs could show strand selectivity; DsiRNA I has similar selectivity for either strand, but DsiRNA II has more substantial activity on the antisense strand (17). We added a 5'GAAA-3' tetra-loop (TL) into each DsiRNA and synthesized different stem structures for each, one with a GC-rich stem (TL_DI and TL_DII), and another with the original stem (TL_DI_O and TL_DII_O), which corresponds to the hnRNPH1 target gene.

\section{Generation of Dicer knockout HCT116 cells}

We previously showed that chemically synthesized 25- to 27-nt-long DsiRNAs interacted with Dicer to facilitate the loading of small RNAs into RISC (27). DsiRNAs increased the gene silencing effect up to 100 times more efficiently than canonical siRNAs (17); recruiting the Dicer enzyme complex using DsiRNAs improves RISC assembly and gene silencing efficacy compared to 21-mer siRNAs. To investigate the effect of tetra-looped DsiRNAs on Dicer efficacy, we generated Dicer knockout cells by transfecting RNA-guided Cas9 endonuclease into the HCT116 cell line. We chose the HCT116 cell line 
because it is not aneuploid and often used for gene knockout studies. To knockout DICER in the human cell line HCT116, we used CRISPR/Cas9 technology. We designed guide RNAs complementary to the area near the genomic locus corresponding to the DExDc of DICER (Figure 2A and B; blue dot and letters). We included an indicator construct containing a green fluorescent protein (GFP) to show specific GFP expression in cells expressing Cas9. To generate a Dicer-deficient derivative of HCT116 cells, we isolated and expanded single-cell clones for further analysis. We obtained a series of three independent clonal cell lines (H2-1, H2-2, H2-3). After single-cell cloning, we purified genomic DNA (gDNA) and performed PCR using gDNA primers (Figure 2B, represented by green or orange arrows; Supplementary Figure 1). We mixed WT PCR product from parental HCT116 cells with Dicer H2 PCR product from single-cell clones of Dicer knockout HCT116 cells in equal quantities to produce heteroduplex molecules. We analyzed the cleavage products by DNA gel electrophoresis. By design, we expected the Surveyor nuclease enzyme to cleave the mismatched nucleotides in the heteroduplex molecule and generate two bands of $962 \mathrm{bp}$ and 196 bp. However, the homodimer PCR products showed the undigested fragment. The Dicer H2-2 clone showed two bands in our electrophoresis assay (Figure 3). This suggested that Dicer H2-2 contained the mismatched nucleotides introduced by the CRISPR/Cas9 system, and it was selected for further analysis.

To confirm whether the mismatched nucleotides were included in the Dicer H2-2 clone, we analyzed the gDNA using Sanger sequencing. Using the CRISPR/Cas9 system, we designed two singleguide RNA (sgRNA; 20 bp: blue letters in Figure 4A) followed by a PAM sequence (orange letters in Figure 4A). We sub-cloned the PCR products, then sequenced each clone. All three clones had altered sequences (Figure 4B). Subsequent sequence analysis confirmed that the CRISPR/Cas9 system introduced DNA double-strand breaks at the target genomic sequences and thereby induced indels via error-prone nonhomologous end-joining repair (28).

\section{Tetra-looped DsiRNA enhanced siRNA efficacy}


To investigate the efficacy of tetra-looped DsiRNA, we used dual-luciferase assays in WT HCT116 cells to separately detect the level of gene silencing conferred by the antisense or sense strand. We normalized the relative firefly luciferase activity of the DsiRNAs by dividing by renilla luciferase as an internal control, then converted 100 value of vector control. We first confirmed the suppression efficiency of DsiRNA in WT HCT116 cells. The DsiRNA I sense strand showed more significant suppression activity than the antisense strand (Figure 5A); in contrast, the DSiRNA II antisense strand was more effective than the DsiRNA II sense strand (Figure 5B). The inclusion of tetra-looped DsiRNAs did not change strand selectivity in WT HCT116 cells (Supplementary Figure 2). Next, we evaluated the silencing effect of each strand of tetra-looped DsiRNAs in WT HCT116 cells. The gene-silencing potency of tetra-looped DsiRNA significantly increased on the preferred strand for the DsiRNA I sense strand (Figure 5C) and DsiRNA II antisense strand (Figure 5F). However, RNAi activity was inconsistent on the non-preferred antisense strand of DsiRNA I and sense strand of DsiRNA II (Figure 5D and E). We designed a nick break between nucleotide bonds that we expected to be cut by Dicer and added tetra-loops to the DsiRNA. On the other hand, an intact guide strand is not necessary for cleavage by Dicer. The resulting increase in gene silencing activity of tetra-looped DsiRNAs might from RISC as a nick break on the guide strand makes it easily unwound. These findings suggest that the tetra-looped DsiRNAs are more efficient for gene silencing than the original DsiRNAs.

\section{Gene silencing activity is controlled by Dicer}

To confirm that Dicer is the main protein involved in small RNA biogenesis, we transfected the DsiRNAs and tetra-looped DsiRNAs into WT HCT116 cells and H2-2 Dicer knockout HCT116 cells. We conducted luciferase assays to quantitate gene silencing. If DsiRNA-induced gene silencing does not occur through Dicer, we would expect equivalent levels of luciferase activity in both WT HCT116 and H2-2 Dicer knockout cells. However, all strands of DsiRNAs, including tetra-looped DsiRNAs, showed significantly reduced gene silencing activity in H2-2 Dicer knockout cells compared to WT HCT116 cells (Figure 6). 
bioRxiv preprint doi: https://doi.org/10.1101/2020.04.19.049817; this version posted April 20, 2020. The copyright holder for this preprint (which

was not certified by peer review) is the author/funder, who has granted bioRxiv a license to display the preprint in perpetuity. It is made available under aCC-BY-NC-ND 4.0 International license.

These results show that Dicer processing is essential to small RNA-mediated gene silencing of both DsiRNAs and tetra-looped DsiRNAs. 


\section{Discussion}

In this study, we evaluated the gene silencing activity of DsiRNAs and tetra-looped DsiRNAs in WT and H2-2 HCT116 cells to better understand Dicer mechanisms. We found that the preferred strand of tetra-looped DsiRNA improves RNAi gene silencing activity (Figure 5). Previously, shRNA, which has a stem-loop structure, was shown to induce stable and long-lasting gene silencing activity (29-31). The RNAi gene silencing activity of shRNAs with stem-loop structures requires Dicer activity (23), possibly because the terminal loops of shRNA and pre-miRNAs share similar RNA structures, which interact with the Nterminal helicase domain of Dicer (25,32-34). Our results suggest that tetra-loop structures are involved in essential Dicer ribonuclease functions, and may have potential alternative effects through interaction with RNA and protein. Other studies of Dicer and pre-miRNA crystal structural analysis revealed that the Nterminal domain of Dicer binds the more stable region of single-stranded hairpin looped pre-miRNA (3537). The N-terminal domain of Dicer is bound to TRBP, which advances the RNA-binding affinity of Dicer (38) and reinforces cleavage accuracy $(39,40)$. We predict that Dicer possesses not only ribonuclease activity but can also affect RNA stability and that TRBP is an RNA cofactor for Dicer complexes, such as for DsiRNA with tetra-loops, which can increase gene silencing activity. This suggestion agrees with previous reports indicating that Dicer can globally bind to stem-looped RNAs without cleavage activity and influences the fate of targeted transcripts by gene silencing (41). Based on the experimental data presented here, DsiRNAs with added tetra-loops showed higher efficiency in gene silencing, but this activity disappeared in Dicer knockout HCT116 cells (Figures 5 and 6). This finding suggests a potential complex in which the stem-loop structure of small RNA and Dicer can improve gene silencing activity.

Dicer is an essential protein for small RNA biogenesis and has recently been reported to act as a multifunctional protein which is not limited in miRNA and siRNA (42). The processing of long transfer RNAs (tRNAs) to small RNAs, broadly termed tRNA fragments (tRFs), is dependent on Dicer (43-45). Sno-derived RNAs (sdRNAs), which are derived from small nucleolar RNAs (snoRNAs), showed reduced expression in Dicer mutants $(46,47)$. The depletion of most miRNA species is detected following Dicer 
ablation (48). Our study provides evidence that tetra-loop DsiRNAs exhibit more potent gene silencing that depends on Dicer (Figure 6). We thus speculate that Dicer is not only identified by its endonuclease activity for small RNAs but also can be stably bound with tetra-looped DsiRNA to enhance gene silencing activity.

Our observations raise intriguing questions regarding the mechanism of how Dicer improves the activity of RNA gene silencing. Interestingly, Dicer can bind to many classes of RNA molecules, in which the interaction does not necessarily lead to dicing. Specific stem-loop structures that bind with Dicer have been identified by human transcriptome-wide analysis and are called "passive Dicer-binding sites" (41). Dicer is believed to participate in the correct guide strand for Ago2 loading to generate RISC $(49,50)$. Our finding suggests that Dicer can generate its own siRNA and can function to stabilize small RNA. We conclude that Dicer-mediated processing of tetra-looped DsiRNAs subsequently facilitates a more stable interaction and improved efficiency. 


\section{Experimental precedures}

\section{DsiRNA duplex}

All RNA strands for DsiRNAs were synthesized as single-strand RNAs (ssRNAs) by Integrated DNA Technologies with high-performance liquid chromatography purification and resuspended in RNase-free water (Table 1). ssRNAs were annealed to form DsiRNA duplexes at $95^{\circ} \mathrm{C}$ for 5 minutes, then incubated for 4 hours at room temperature, before being aliquoted $(10 \mu \mathrm{L}$ in $1.5-\mathrm{mL}$ tube) and stored at $80^{\circ} \mathrm{C}$.

\section{Cell culture and transfection}

HCT116 cells were cultured in DMEM supplemented with 10\% fetal bovine serum and penicillinstreptomycin at $37^{\circ} \mathrm{C}$ in $5 \% \mathrm{CO}_{2}$ with humidification. HCT116 cells were transfected with Lipofectamine 2000 (Life Technologies). The Dicer knockout HCT116 cells were generated by employing CRISPR technology (DICER Double Nickase plasmid h2, Santa Cruz, sc-400365-NIC-2 following the manufacturer's protocol. The DICER genome sequence and sgRNA targets are represented in Figure 2.

\section{Dual-luciferase assay}

To generate the reporter plasmids psi-hnRNPH-S (sense reporter) and psi-hnRNPH-AS (antisense reporter), a 343-bp PCR fragment of hnRNPH cDNA (Acc.: NM_005520) was cloned in the 3'-UTR of the humanized Renilla luciferase gene in the psiCHECKTM-2 vector (Promega) in either the sense or antisense orientation. The cells were co-transfected with $0.1 \mu \mathrm{g}$ of the plasmid with the dual-luciferase reporter system and DsiRNAs using $2 \mu \mathrm{l}$ of Lipofectamine 2000 in a 48 -well plate. Luciferase assays were performed 48 hours after transfection, using the dual-luciferase reporter assay system (Promega). Firefly 
Luciferase activity was normalized to the Renilla Luciferase activity and then to its own control, the activity of which was set to 100 .

\section{Surveyor nuclease assay}

We purified gDNA from CRISPR/Cas9-treated HCT116 cells to confirm Dicer knockout. We amplified segments containing the sgRNA target site by PCR, using $100 \mathrm{ng}$ gDNA with a representative primer shown in Figure 2B. We purified the DNA from PCR products, then mixed 300 ng PCR products obtained from WT and Dicer knockout mutant HCT116 cells, and denatured them by heating at $99^{\circ} \mathrm{C}$ for 5 min in a thermocycler. We then formed heteroduplexes and homoduplexes by cooling down to room temperature.

We performed the Surveyor nuclease assay using a Surveyor ${ }^{\circledR}$ mutation detection kit (IDT). We mixed each sample with $1 \mu \mathrm{L}$ of Surveyor Enhancer $S, 1 \mu \mathrm{L}$ of SURVEYOR nuclease S, and $4 \mu \mathrm{L}$ of 0.15 $\mathrm{M} \mathrm{MgCl} 2$ in a $50-\mu \mathrm{L}$ reaction. We incubated the mix for $60 \mathrm{~min}$ at $42^{\circ} \mathrm{C}$ and stopped the reaction by adding $4 \mu \mathrm{L}$ of the stop solution provided in the kit. The reactions were either kept at $-20^{\circ}$ or used immediately for electrophoresis.

\section{Statistical analysis}

Statistical analyses were performed using Student's t-test. All data represent the mean \pm SD of at least three independent experiments. 


\section{Footnotes}

This study was supported by Cancer Center Support Grant 033572 and National Institute of Health

AI042552 ( to J. J. R.). The authors declare that they have no conflicts of interest with the contents of this article.

The abbreviations used are:

DsiRNA: Dicer-substrate siRNA

rRNA: ribosomal RNA

dsRNAs: double-stranded RNAs

siRNAs: small interfering 21-22bp RNAs

RISC: RNA-induced silencing complex

miRNA: microRNA

pri-miRNA: hairpin-containing primary transcripts

shRNAs: short hairpin RNAs

DExD: DEAD-like helicases domain

TRBP: transactivation response element RNA-binding protein

WT: wild-type

RNAi: RNA interference

hnRNPH1: heterogeneous nuclear ribonucleoprotein $\mathrm{H}$

TL: tetra-loop

GFP: green fluorescent protein

gDNA: genomic DNA

sgRNA: single-guide RNA 


\section{References}

1. Soukup, G. A. (2003) Nucleic acids: general properties. In eLS, (Ed.).

2. Chen, Y., and Varani, G. (2010) RNA Structure, In eLS, (Ed.)

3. Cheong, C., and Cheong, H.-K. (2010) RNA Structure: Tetraloops. In eLS, (Ed.).

4. Antao, V. P., and Tinoco, I., Jr. (1992) Thermodynamic parameters for loop formation in RNA and DNA hairpin tetraloops. Nucleic acids research 20, 819-824

5. Wolters, J. (1992) The nature of preferred hairpin structures in 16S-like rRNA variable regions. Nucleic acids research 20, 1843-1850

6. Fourmy, D., Guittet, E., and Yoshizawa, S. (2002) Structure of prokaryotic SECIS mRNA hairpin and its interaction with elongation factor SelB. Journal of molecular biology 324, 137-150

7. Du, Z., Yu, J., Andino, R., and James, T. L. (2003) Extending the Family of UNCG-like Tetraloop Motifs: NMR Structure of a CACG Tetraloop from Coxsackievirus B3. Biochemistry 42, 4373-4383

8. Girard, F. C., Ottink, O. M., Ampt, K. A. M., Tessari, M., and Wijmenga, S. S. (2007) Thermodynamics and NMR studies on Duck, Heron and Human HBV encapsidation signals. Nucleic acids research 35, 2800-2811

9. Kieft, J. S., and Tinoco, I., Jr. (1997) Solution structure of a metal-binding site in the major groove of RNA complexed with cobalt (III) hexammine. Structure (London, England : 1993) 5, 713-721

10. Wu, H., Yang, P. K., Butcher, S. E., Kang, S., Chanfreau, G., and Feigon, J. (2001) A novel family of RNA tetraloop structure forms the recognition site for Saccharomyces cerevisiae RNase III. The EMBO journal 20, 7240-7249

11. Varani, G. (1995) Exceptionally stable nucleic acid hairpins. Annual review of biophysics and biomolecular structure 24, 379-404

12. Jucker, F. M., Heus, H. A., Yip, P. F., Moors, E. H., and Pardi, A. (1996) A network of heterogeneous hydrogen bonds in GNRA tetraloops. Journal of molecular biology 264, 968-980

13. Cheong, C., Varani, G., and Tinoco, I. (1990) Solution structure of an unusually stable RNA hairpin, 5GGAC(UUCG)GUCC. Nature 346, 680-682

14. Legault, P., Li, J., Mogridge, J., Kay, L. E., and Greenblatt, J. (1998) NMR structure of the bacteriophage lambda N peptide/boxB RNA complex: recognition of a GNRA fold by an argininerich motif. Cell 93, 289-299

15. Tinoco, I., Jr., and Bustamante, C. (1999) How RNA folds. Journal of molecular biology 293, 271281

16. Kim, D. H., Behlke, M. A., Rose, S. D., Chang, M. S., Choi, S., and Rossi, J. J. (2005) Synthetic dsRNA Dicer substrates enhance RNAi potency and efficacy. Nat Biotechnol 23, 222-226

17. Snead, N. M., Wu, X., Li, A., Cui, Q., Sakurai, K., Burnett, J. C., and Rossi, J. J. (2013) Molecular basis for improved gene silencing by Dicer substrate interfering RNA compared with other siRNA variants. Nucleic acids research 41, 6209-6221

18. Rose, S. D., Kim, D.-H., Amarzguioui, M., Heidel, J. D., Collingwood, M. A., Davis, M. E., Rossi, J. J., and Behlke, M. A. (2005) Functional polarity is introduced by Dicer processing of short substrate RNAs. Nucleic acids research 33, 4140-4156

19. Hefner, E., Clark, K., Whitman, C., Behlke, M. A., Rose, S. D., Peek, A. S., and Rubio, T. (2008) Increased potency and longevity of gene silencing using validated Dicer substrates. Journal of biomolecular techniques : JBT 19, 231-237

20. Kubo, T., Zhelev, Z., Ohba, H., and Bakalova, R. (2007) Modified 27-nt dsRNAs with dramatically enhanced stability in serum and long-term RNAi activity. Oligonucleotides 17, 445-464

21. Dudek, H., Wong, D. H., Arvan, R., Shah, A., Wortham, K., Ying, B., Diwanji, R., Zhou, W., Holmes, B., Yang, H., Cyr, W. A., Zhou, Y., Shah, A., Farkiwala, R., Lee, M., Li, Y., Rettig, G. R., Collingwood, M. A., Basu, S. K., Behlke, M. A., and Brown, B. D. (2014) Knockdown of \&\#x3b2;-catenin with 
Dicer-Substrate siRNAs Reduces Liver Tumor Burden $<$ em $>$ In vivo $</ e m>$. Molecular Therapy 22, 92-101

22. Bobbin, M. L., and Rossi, J. J. (2016) RNA Interference (RNAi)-Based Therapeutics: Delivering on the Promise? Annual review of pharmacology and toxicology 56, 103-122

23. Gu, S., Jin, L., Zhang, Y., Huang, Y., Zhang, F., Valdmanis, P. N., and Kay, M. A. (2012) The loop position of shRNAs and pre-miRNAs is critical for the accuracy of dicer processing in vivo. Cell 151, 900-911

24. Herrera-Carrillo, E., Harwig, A., and Berkhout, B. (2017) Influence of the loop size and nucleotide composition on AgoshRNA biogenesis and activity. RNA Biology 14, 1559-1569

25. Liu, Z., Wang, J., Cheng, H., Ke, X., Sun, L., Zhang, Q. C., and Wang, H. W. (2018) Cryo-EM Structure of Human Dicer and Its Complexes with a Pre-miRNA Substrate. Cell 173, 11911203.e1112

26. Sakurai, K., Amarzguioui, M., Kim, D. H., Alluin, J., Heale, B., Song, M. S., Gatignol, A., Behlke, M. A., and Rossi, J. J. (2011) A role for human Dicer in pre-RISC loading of siRNAs. Nucleic acids research 39, 1510-1525

27. Kim, D.-H., Behlke, M. A., Rose, S. D., Chang, M.-S., Choi, S., and Rossi, J. J. (2005) Synthetic dsRNA Dicer substrates enhance RNAi potency and efficacy. Nat Biotech 23, 222-226

28. Ran, F. A., Hsu, P. D., Lin, C.-Y., Gootenberg, J. S., Konermann, S., Trevino, A. E., Scott, D. A., Inoue, A., Matoba, S., Zhang, Y., and Zhang, F. (2013) Double nicking by RNA-guided CRISPR Cas9 for enhanced genome editing specificity. Cell 154, 1380-1389

29. Rossi, J. J. (2008) Expression strategies for short hairpin RNA interference triggers. Hum Gene Ther 19, 313-317

30. McCaffrey, A. P., Meuse, L., Pham, T. T., Conklin, D. S., Hannon, G. J., and Kay, M. A. (2002) RNA interference in adult mice. Nature 418, 38-39

31. Brummelkamp, T. R., Bernards, R., and Agami, R. (2002) A system for stable expression of short interfering RNAs in mammalian cells. Science (New York, N.Y.) 296, 550-553

32. Pokornowska, M., Milewski, M. C., Ciechanowska, K., Szczepanska, A., Wojnicka, M., Radogostowicz, Z., Figlerowicz, M., and Kurzynska-Kokorniak, A. (2019) The RNA-RNA base pairing potential of human Dicer and Ago2 proteins. Cellular and molecular life sciences : CMLS

33. Hansen, S. R., Aderounmu, A. M., Donelick, H. M., and Bass, B. L. (2020) Dicer's Helicase Domain: A Meeting Place for Regulatory Proteins. Cold Spring Harbor symposia on quantitative biology

34. Park, J. E., Heo, I., Tian, Y., Simanshu, D. K., Chang, H., Jee, D., Patel, D. J., and Kim, V. N. (2011) Dicer recognizes the $5^{\prime}$ end of RNA for efficient and accurate processing. Nature 475, 201-205

35. Tian, Y., Simanshu, D. K., Ma, J. B., Park, J. E., Heo, I., Kim, V. N., and Patel, D. J. (2014) A phosphate-binding pocket within the platform-PAZ-connector helix cassette of human Dicer. Molecular cell 53, 606-616

36. Taylor, D. W., Ma, E., Shigematsu, H., Cianfrocco, M. A., Noland, C. L., Nagayama, K., Nogales, E., Doudna, J. A., and Wang, H. W. (2013) Substrate-specific structural rearrangements of human Dicer. Nature structural \& molecular biology 20, 662-670

37. Kandasamy, S. K., and Fukunaga, R. (2016) Phosphate-binding pocket in Dicer-2 PAZ domain for high-fidelity siRNA production. Proceedings of the National Academy of Sciences of the United States of America 113, 14031-14036

38. Chakravarthy, S., Sternberg, S. H., Kellenberger, C. A., and Doudna, J. A. (2010) Substrate-Specific Kinetics of Dicer-Catalyzed RNA Processing. Journal of molecular biology 404, 392-402

39. Kim, Y., Yeo, J., Lee, J. H., Cho, J., Seo, D., Kim, J. S., and Kim, V. N. (2014) Deletion of human tarbp2 reveals cellular microRNA targets and cell-cycle function of TRBP. Cell Rep 9, 1061-1074

40. Fukunaga, R., Han, B. W., Hung, J. H., Xu, J., Weng, Z., and Zamore, P. D. (2012) Dicer partner proteins tune the length of mature miRNAs in flies and mammals. Cell 151, 533-546 
41. Rybak-Wolf, A., Jens, M., Murakawa, Y., Herzog, M., Landthaler, M., and Rajewsky, N. (2014) A Variety of Dicer Substrates in Human and C. elegans. Cell 159, 1153-1167

42. Song, M.-S., and Rossi, J. J. (2017) Molecular mechanisms of Dicer: endonuclease and enzymatic activity. Biochemical Journal 474, 1603-1618

43. Cole, C., Sobala, A., Lu, C., Thatcher, S. R., Bowman, A., Brown, J. W. S., Green, P. J., Barton, G. J., and Hutvagner, G. (2009) Filtering of deep sequencing data reveals the existence of abundant Dicer-dependent small RNAs derived from tRNAs. RNA 15, 2147-2160

44. Kumar, P., Kuscu, C., and Dutta, A. (2016) Biogenesis and Function of Transfer RNA-Related Fragments (tRFs). Trends in Biochemical Sciences 41, 679-689

45. Li, Z., Ender, C., Meister, G., Moore, P. S., Chang, Y., and John, B. (2012) Extensive terminal and asymmetric processing of small RNAs from rRNAs, snoRNAs, snRNAs, and tRNAs. Nucleic acids research 40, 6787-6799

46. Taft, R. J., Glazov, E. A., Lassmann, T., Hayashizaki, Y., Carninci, P., and Mattick, J. S. (2009) Small RNAs derived from snoRNAs. RNA 15, 1233-1240

47. Ender, C., Krek, A., Friedlander, M. R., Beitzinger, M., Weinmann, L., Chen, W., Pfeffer, S., Rajewsky, N., and Meister, G. (2008) A human snoRNA with microRNA-like functions. Molecular cell 32, 519-528

48. Kim, Y. K., Kim, B., and Kim, V. N. (2016) Re-evaluation of the roles of DROSHA, Export in 5, and DICER in microRNA biogenesis. Proceedings of the National Academy of Sciences of the United States of America 113, E1881-1889

49. Wilson, R. C., Tambe, A., Kidwell, M. A., Noland, C. L., Schneider, C. P., and Doudna, J. A. (2015) Dicer-TRBP complex formation ensures accurate mammalian microRNA biogenesis. Molecular cell 57, 397-407

50. Noland, C. L., Ma, E., and Doudna, J. A. (2011) siRNA repositioning for guide strand selection by human Dicer complexes. Molecular cell 43, 110-121 


\section{Figure Legend}

\section{Figure 1. Structure of hnRNPH1-targeting DsiRNAs and tetra-looped DsiRNAs}

We designed two DsiRNAs targeting hnRNPH1, DsiRNA I (DI) and DsiRNA II (DII), then designed tetralooped versions. The tetra-looped DsiRNA I (TL_DI) has a 21-mer sense strand and 38-mer antisense strand, with a GC rich stem and 5'-GAAA-3' tetra-loop (represented with blue circles). The tetra-looped DsiRNA I Original (TL_DI_O) has the same sequence as DI, with a 5'-GAAA-3' loop sequence ( blue circles). The tetra-looped DsiRNA II (TL_DII) has a 22-mer antisense strand and 36-mer sense strand, with a GC rich stem and GAAA tetra-loop (blue circles). The tetra-looped DsiRNA II Original (TL_DII_O) has the same sequence as DII, with a GAAA loop sequence (blue circles). The detailed sequences are listed in Table 1. Ribonucleotides are shown in upper case and deoxyribonucleotides as $\mathrm{dN}$. The purple underlined sequence shows the active strand. The blue arrow indicates the nick between ribonucleotides.

\section{Figure 2. Dicer mutation by CRISPR/Cas9 system}

A. Domain structure of Dicer protein. Blue rectangles indicate the regions corresponding to the genomic DNA (gDNA) sequences targeted by the CRISPR/Cas9 system. B: Sequence of Dicer gDNA. The two sites with blue letters show the sequence targeted by double-nickase CRISPR. Green and red arrows indicate primers for detecting Dicer gDNA.

Figure 3. SURVEYOR assay comparing the efficiency of Cas9-mediated cleavage by double-nickase sgRNA in the human Dicer locus.

DNA duplex formation and treatment with a nuclease. SURVEYOR assay gel showing a comparable modification of control G/C, which is 633 base pair (bp) Control DNA with a point mutation (Supplementary Figure 1B) bearing 416bp and 217bp. Homo duplex without mismatch did not cleave the 
nuclease, but hetero duplex (Dicer H2-1, H2-2, and H2-3) show the cleavage band. We run the gel short (A) and long (B) running. Arrowheads indicate cleavage products.

\section{Figure 4. A representative sequence of the human DICER locus targeted by Cas9.}

A. Schematic illustrating DNA double nickase using a pair of sgRNAs guiding Cas9 nickase. Cas9 can cleave only the strand complementary to the sgRNA (Blue letters). A pair of sgRNA-Cas9 able to cleave Dicer gDNA. Expected cleavage site marks as Red arrow, respectively. sgRNA offset is characterized as the distance between the PAM (brown letters)- 5'-ends of the guide sequence of a given sgRNA pair. The brown letters are the PAM sequence. The red arrow is an expected cleave site by Cas9. B. Representative sequences of the genomic DNA in the helicase domain of human Dicer targeted by sgRNA. PAM area represents a red under-lined dot (upper) and boxed (bottom). The dotted vertical line is the expected cleavage site. We compared H2-2 clone sequence with the human Dicer genomic DNA sequence. The negative control is the gDNA sequence from WT HCT116.

\section{Figure 5. DsiRNAs efficacy in HCT116.}

Reporters contain the Renilla luciferase 3' UTR of Antisense(AS_GS) or sense(S_PS) of hnRNPH1 transcript. Relative expression of the reporter with Firefly and Renilla luciferase determined by dualluciferase assay. The internal control is the value of firefly luciferase. The Renilla activities were normalized to those of firefly and arbitrarily set at 100. Mean values and standard deviations from three independent experiments are shown. (student t-test $* \mathrm{P}<0.05$, $* * \mathrm{P}<0.01$, *** $\mathrm{P}<0.001$, and $* * * * \mathrm{P}<0.0001$ ) We transfected dual-luciferase reporter and variant DsiRNAs into HCT116. The DsiRNA represent A. DsiRNA I, B. DsiRNA II, C: DsiRNA I_S, D: DsiRNA II_S, E: DsiRNA I_AS, and F:DsiRNA II_AS. 


\section{Figure 6. Compare with DsiRNAs efficacy in HCT116 and H2-2.}

The detection method was the same as Figure 6. We transfected the dual-luciferase reporter (S: vector with targeting sense strand of DsiRNAs, AS reporter with targeting antisense strand of DsiRNAs) and DsiRNAs into HCT116 and H2-2 (Dicer knockout HCT116: red bar). We detected the fold decrease of gene silencing efficiency in H2-2A to calculated the activity of H2-2 divided by HCT116 (green bar). It represented the right $y$-axis. The graphs showed the gene silencing activity of A: sense strand of DI (S-DI), B: sense strand of DI_TL (S-DI_TL), C: sense strand of DI_TL_O (S-DI_TL_O), D: sense strand of DII (S-DII), E: S of DII_TL (S-DII_TL), F: S of DII_TL_O (S-DII_TL_O), G: antisense strand of DI (AS-DI), H: antisense strand of DI_TL )AS-DI_TL), I: antisense of DI_TL_O (AS-DI_TL_O), J: antisense of DII (AS-DII), K: antisense of DII_TL (AS-DII_TL), and L: antisense of DII_TL_O (AS-DII_TL_O). Data represent the mean \pm S.D. of three independent repeats. An asterisk indicates statically significant differences at the level of $* \mathrm{P}<0.05, * * \mathrm{P}<0.01, * * * \mathrm{P}<0.001$, and $* * * * \mathrm{P}<0.0001$ tested by student's t-test.

\section{Table 1. The sequence of each strand of DsiRNAs}

DsiRNA sequences used to synthesize the tetra-looped DsiRNAs.

\section{Supplementary Figure 1. Genomic DNA PCR from single-clone cells}

A.PCR using genomic DNA for single cell clone of H2-1, H2-2, and H2-3 (1158bp), control C, and control $\mathrm{G}$ (633bp). B. The sequence presents the control DNA sequence. Yellow marked G is point mutation site, it is G or C. Red letter and under line is forward and Reverse primer site for gDNA PCR

\section{Supplementary Figure 2. Gene silencing activity in each strand of DsiRNAs}


The version of DsiRNA I(A) and DsiRNAII(B) transfected HCT116 cells were lysed in 1X passive lysis buffer, and dual-luciferase activities were determined. We calculated the AS preference for Relative Rlue activity of AS divided by S activity (AS preferency: blue bar). DsiRNA I showed more 2- fold AS preferency. In contrast, the AS preferency of DsiRNA II below 1. DsiRNAIIs have preferred the S strand in DsiRNA II, TL-DsiRNAII, and TL-DsiRNAII-O. The data shown represent the means of three experiments, with the bar showing SD. 


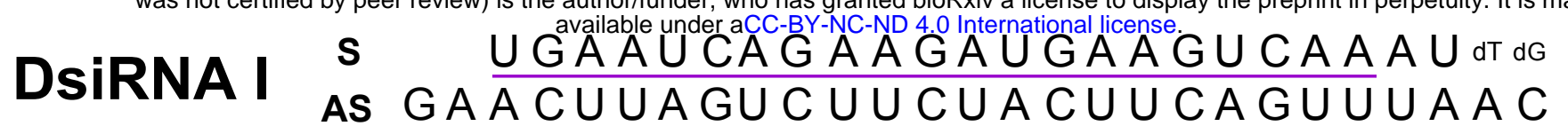

TL_DI

S

(G)

TL_DI_O S

G

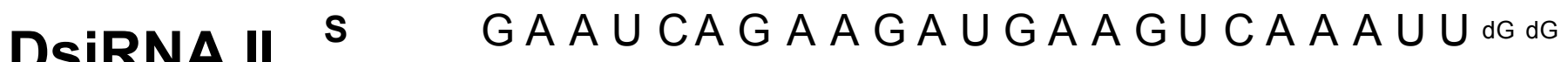
AS $A A C \cup \cup A G \cup C \cup \cup C \cup A C \cup \cup C A G \cup \cup \cup A A C C$

TL_DII

S GAAUCAGA A G U A A U C A AGCAGCC

TL_DII_O

S

$G A A \cup C A G A A G A \cup G A A G \cup C A A A \cup U d G d G$

As $A A C \cup \cup A G \cup C \cup \cup C \cup A C \cup \cup C A G \cup \cup \cup A A C C$ 
bioRxiv preprint doi: https://doi.org/10.1101/2020.04.19.049817; this version posted April 20, 2020. The copyright holder for this preprint (which was not certified by peer review) is the author/funder, who has granted bioRxiv a license to display the preprint in perpetuity. It is made available under aCC-BY-NC-ND 4.0 International license.

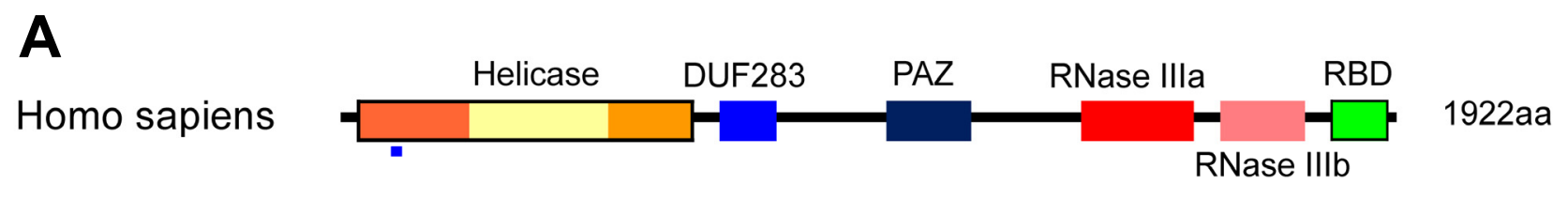

\section{B}

23601 GTGGTAGGCTTTCACACAGATATTTGAATCCCTGACCCTCTGTTTGAAGGGTAGGAATTTTAAAGTTTCAGTTTTTATCATTTTACATAATCAAATTT

23701 CTGTGGGAAAAACTATATGAAATATAGAAAGTGCTTAGATACCATGAAAAAATTTTTATTTCACAGAGTGGTGTCATTTGTTTTAATTTATCTAGGAT.

23801 GTATAATTTTAAAGATACATATTTAAATAGTTGTGCATTTATAATAGGTTGTCAATTGAGAAAAAGGCCTGTGTTCGTGAGCTGTTGATAAAGTGACA

23901 TTTAGCAGGTGTCTAAATCTTTCGTGGTGCAGGCACAGTGCTAAGTGCCTTCCATACATTATCATTTTATCAGTAACGTCATAGAATATACAAAGAAT

24001 TCAAAATTATTTATGTGTATATTTACATATTTTATATATGTACATATATTTAACAAGGCATCATGCTGTACATATTTTCTTTTAAAGGTTTATTATG

24101 CATTGTTCTGTGTCAGGAACTACAgATATGTGCTATAATCTTAATGGATTCAAAGTATTCCATTATATAGTCATAGCATAATTTATGTAGCTTATTTT

24201 ACCAGTAGATTTAAAGTTATTTCTTATTTTTAAGTAATAATGCAACAACAAATATTCATGTACATCTCTTTGTGAAGTTGCTTGATTCATTCTTTAA

24301 CAAATTTCTAGGCATAGAATCACTGGGTAAGGTACAGAATGCTTGACTCCTAAAATGATCCTCTTAGATCAAGAAAAAGCTAAAACAATTATAGGAAG

24401 TTTGAATGGCTCATAGGAATGATATTCTGATGTTTCTCTTGTTTCTGTGCTTTCTTTGTTTTTAACCCTGCATGATTGTGTAATGGTATTCTTTTTCC

24501 TTTGTAGTAAGCTGTGCTAGAACAAAAATGCAATGAAAGAAACACTGGATGAATGAAAAGCCCTGCTTTGCAACCCCTCAGCATGGCAGGCCTGCAGC

24601 ATGACCCCTGCTTCCTCACCAATGGGTCCTTTCTTTGGACTGCCATGGCAACAAGAAGCAATTCATGATAACATTTATACGCCAAGAAAATATCAGGT

24701 TAATGCGAACACTAATACTGGAGCATTCTACACTAAAATGGAATACATTAGCATATAGTTGACACAACTTATATAAAACTCATTTACCCTTTCAGGCC 
A
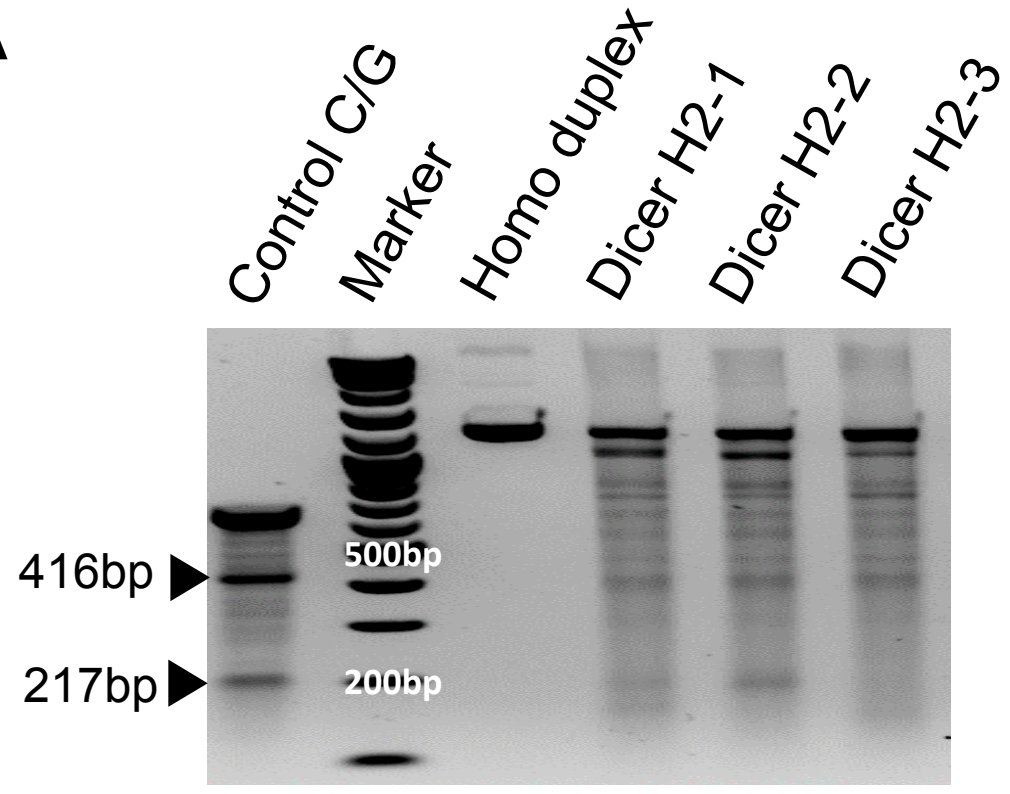

B

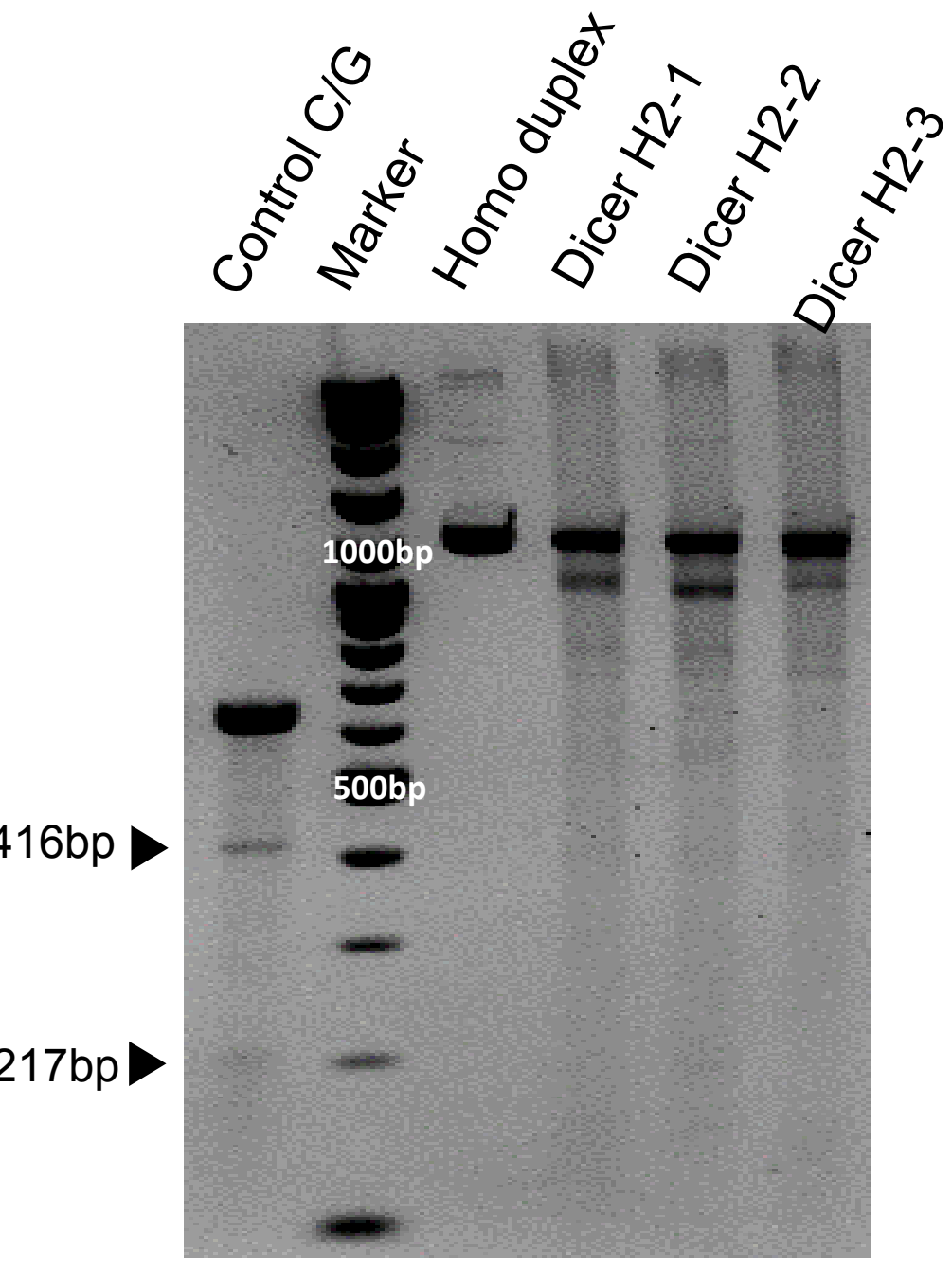


bioRxiv preprint doi: https://doi.org/10.1101/2020.04.19.049817; this version posted April 20, 2020. The copyright holder for this preprint (which was not certified by peer review) is the author/funder, who has granted bioRxiv a license to display the preprint in perpetuity. It is made available under aCC-BY-NC-ND 4.0 International license.

\section{A}

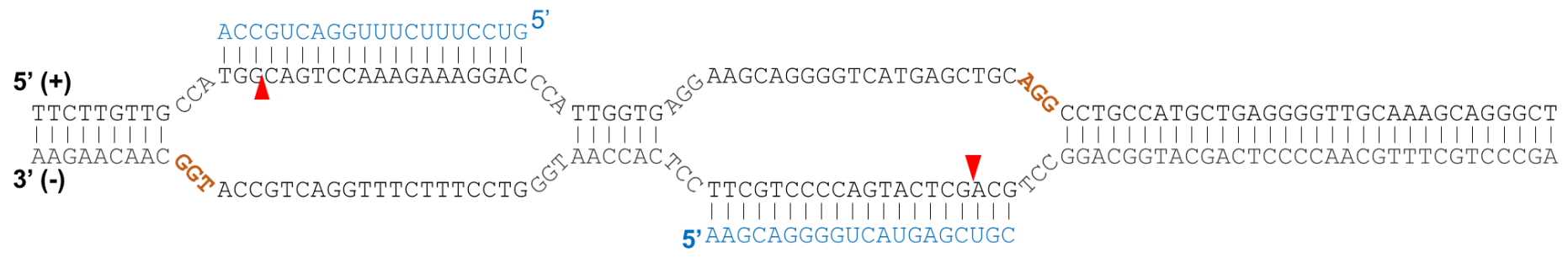

B

5' (+) edited SAmple 138 To 203 BP

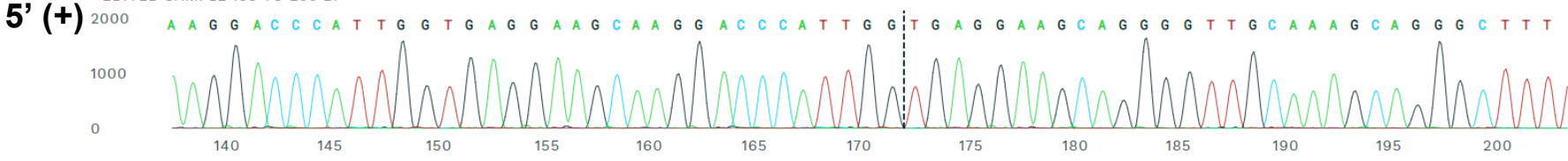
CONTROL SAMPLE 139 TO 204 BP

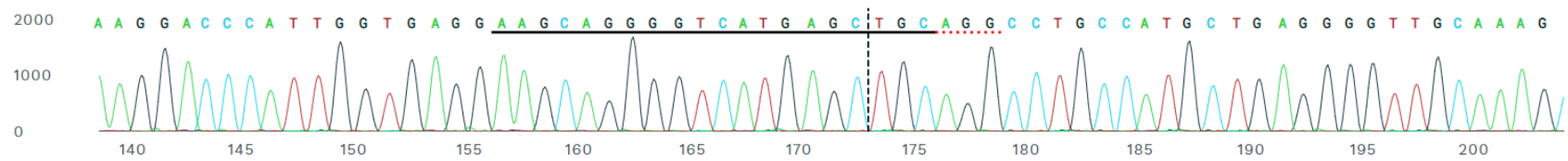

Dicer gDNA fragmant AACACTGGATGAAT GAAAAGCCCT GC TTTGCAACCCC TCAGCA TGGC AGG CCTGCA'GCTCATGACCCC TGCTTCC TCACCAAT G' Consensus AACAC TGGATGAAT GAAAAGCCCT GC TT TGCAACCCCT - . GCT T - . . . . CCT -CA'CCAATGGGTCC TTGCT TCC TCACCAATGG Gap fraction

Negative control AACACTGGATGAAT GAAAAGCCCT GCTT TGCAACCCC TCAGCA TGGCAGG CCT GCA'GC TCAT GACCCC TGCT TCC TCACCAAT GG। H2-2_4 AACACTGGATGAAT GAAAAGCCCTGCTTTGCAACCCCT - GCT T....... CCT - CACCAATGGGTCCTTGCTTCCTCACCAATGG। H2-2 1 AACACTGGATGAAT GAAAAGCCCTGCTTTGCAACCCC T ... GCT T......... CCT -CA'CCAATGGGTCC TTGCTTCCTCACCAATGG H2-2_2 AACACTGGATGAATGAAAAGCCCTGCTTTGCAACCCCT ...GCTT......... CCT. CẠCCAATGGGTCCTTGCTTCCTCACCAATGG! 

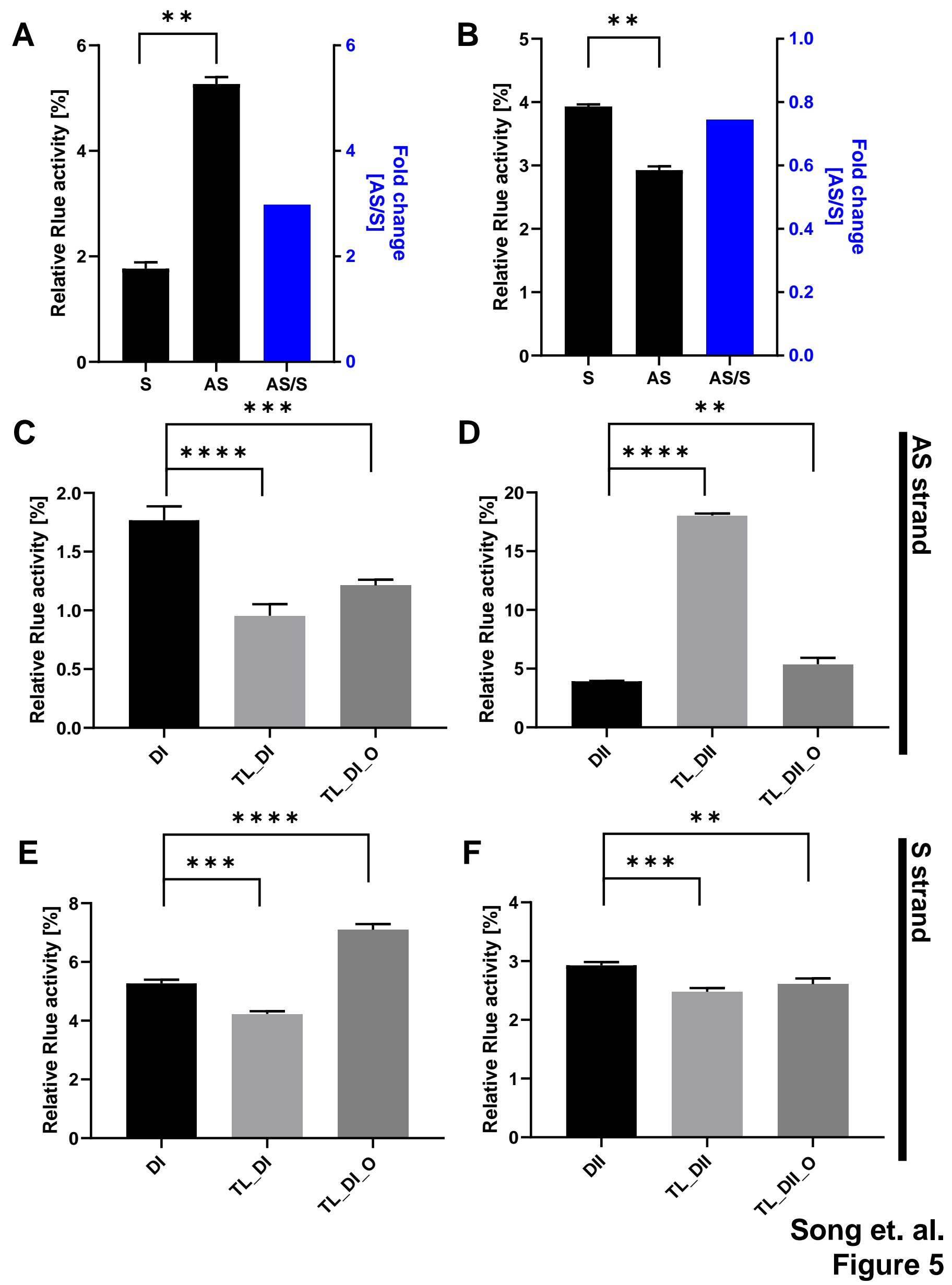


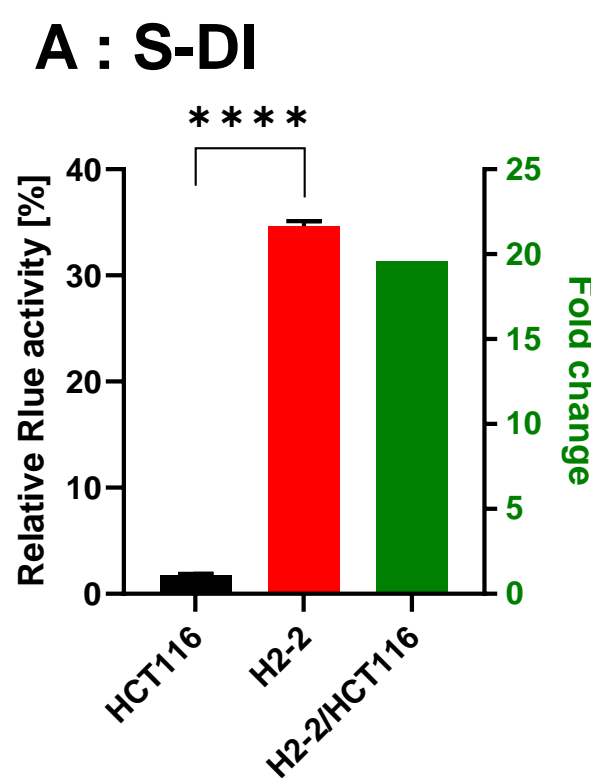

\section{D: S-DII}

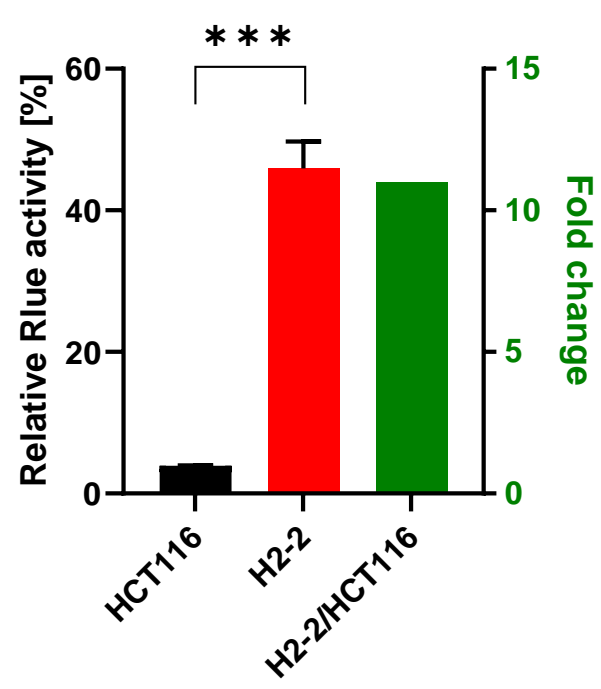

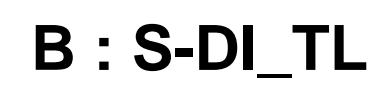
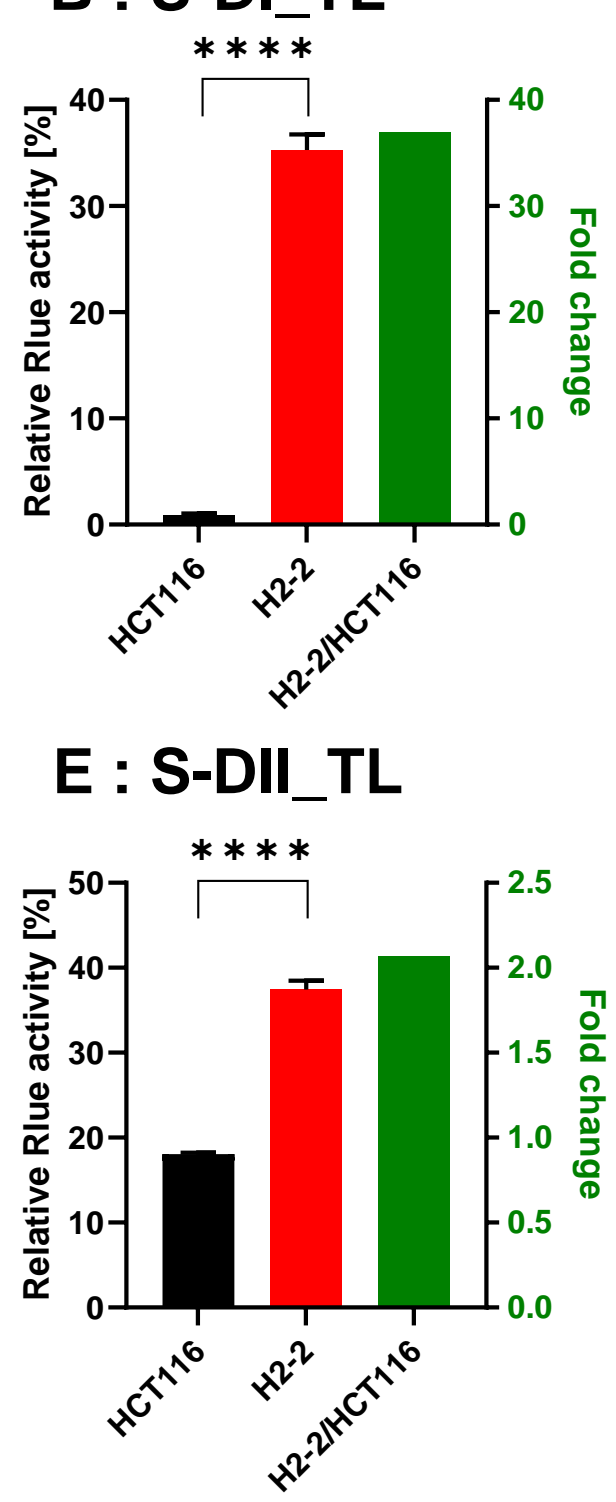

C : S-DI_TL_O

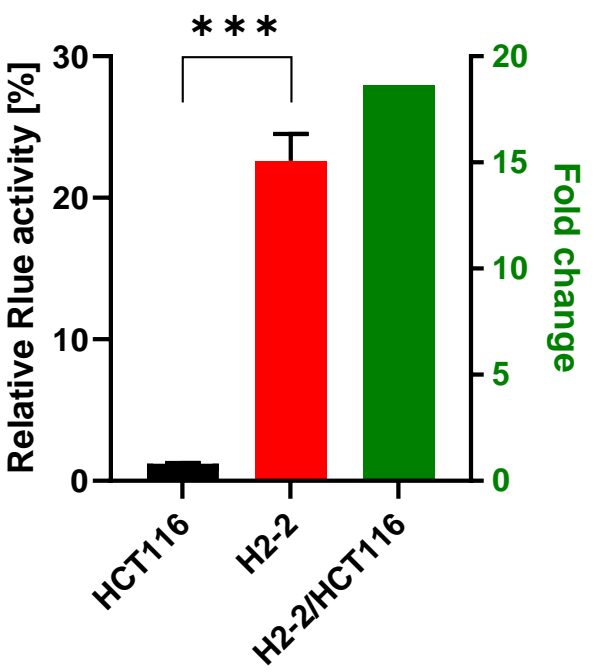

F : S-DII_TK_O

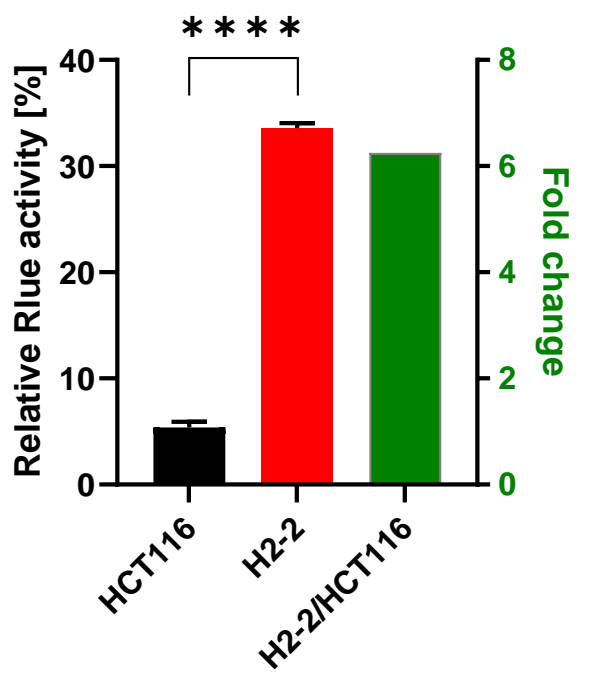




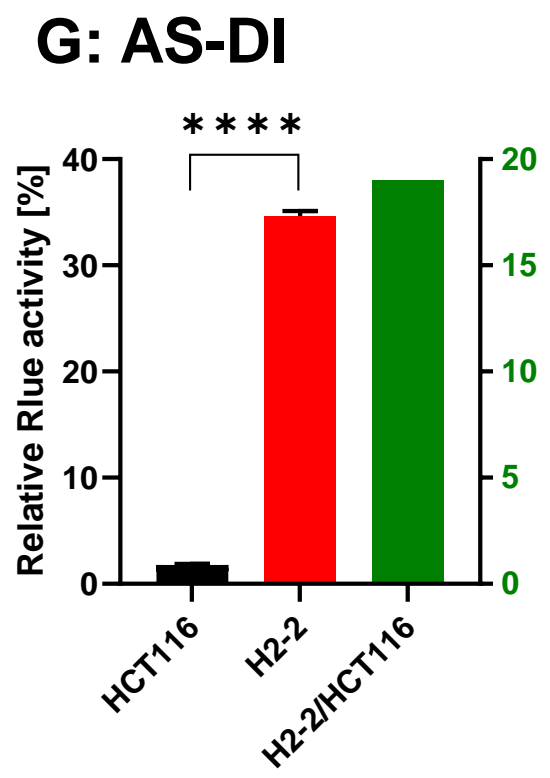

\section{J: AS-DII}

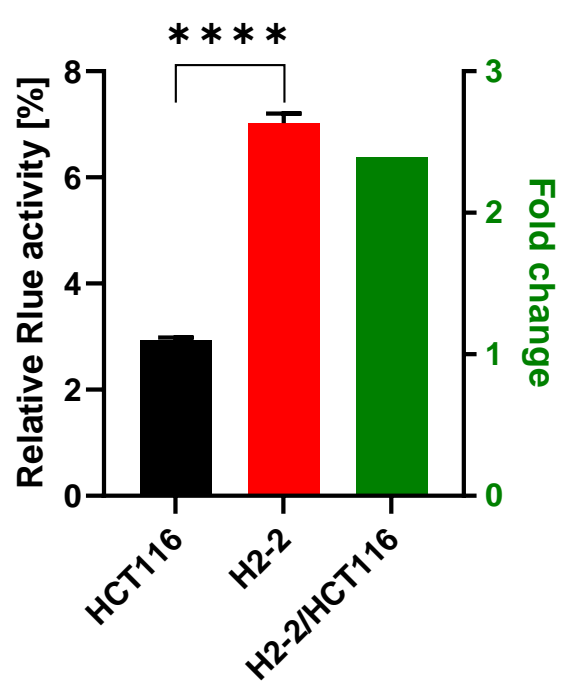

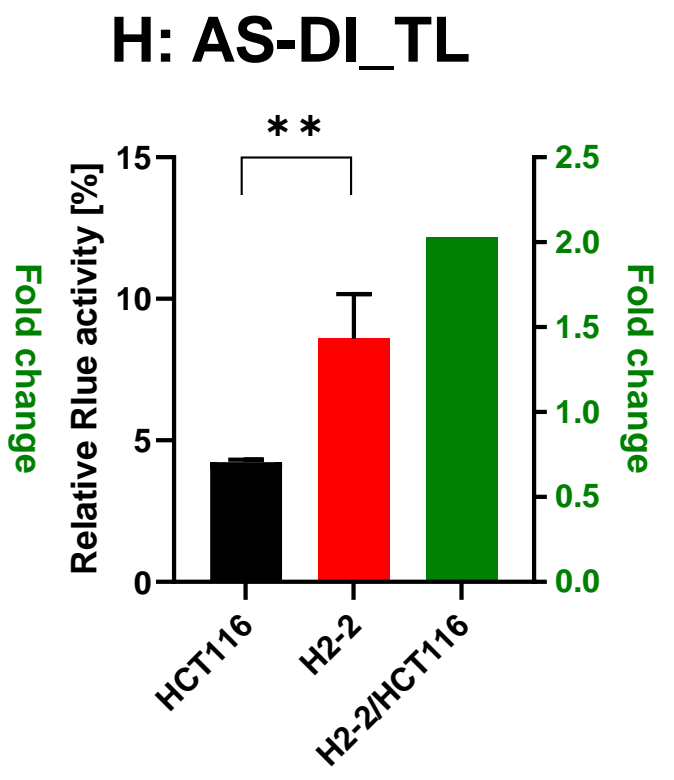

I: AS-DI_TL_O
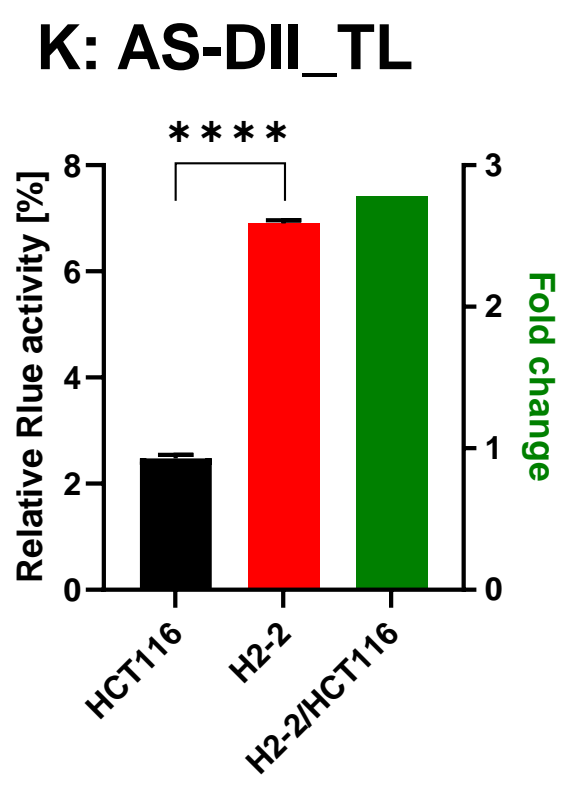

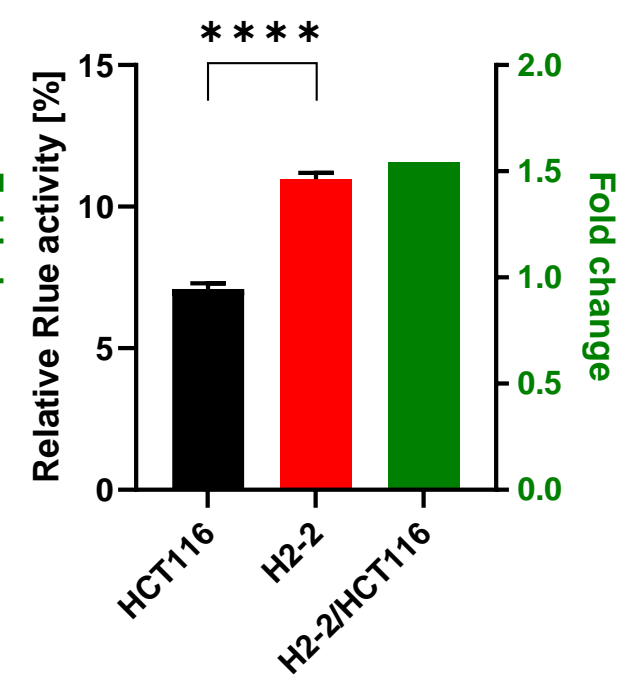

L: AS-DII_TL_O

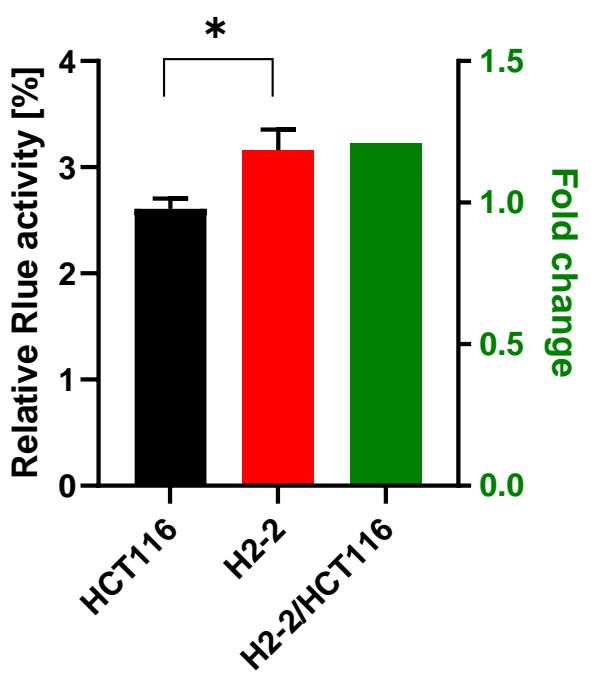




\begin{tabular}{|l|l|l|}
\hline & 5' to 3' $^{\prime}$ & size \\
\hline S-DI & UGAAUCAGAAGAUGAAGUCAA & 21 \\
\hline AS_TL_DI_0 & $\begin{array}{l}\text { AUdTdGGAAACAAUUUGACUUCAUCUUCUGAU } \\
\text { UCAAG }\end{array}$ & 35 \\
\hline AS_TL_DI & $\begin{array}{l}\text { GCAGCCGAAAGGCUGCUUGACUUCAUCUUCUG } \\
\text { AUUCAAG }\end{array}$ & 38 \\
\hline S_TL_DII_O & $\begin{array}{l}\text { GAAUCAGAAGAUGAAGUCAAAUUdGdGGAAAC } \\
\text { CAAU }\end{array}$ & 35 \\
\hline S_TL_DII & $\begin{array}{l}\text { GAAUCAGAAGAUGAAGUCAAGCAGCCGAAAGG } \\
\text { CUGC }\end{array}$ & 36 \\
\hline AS_DII & UUGACUUCAUCUUCUGAUUCAA & 22 \\
\hline
\end{tabular}


A

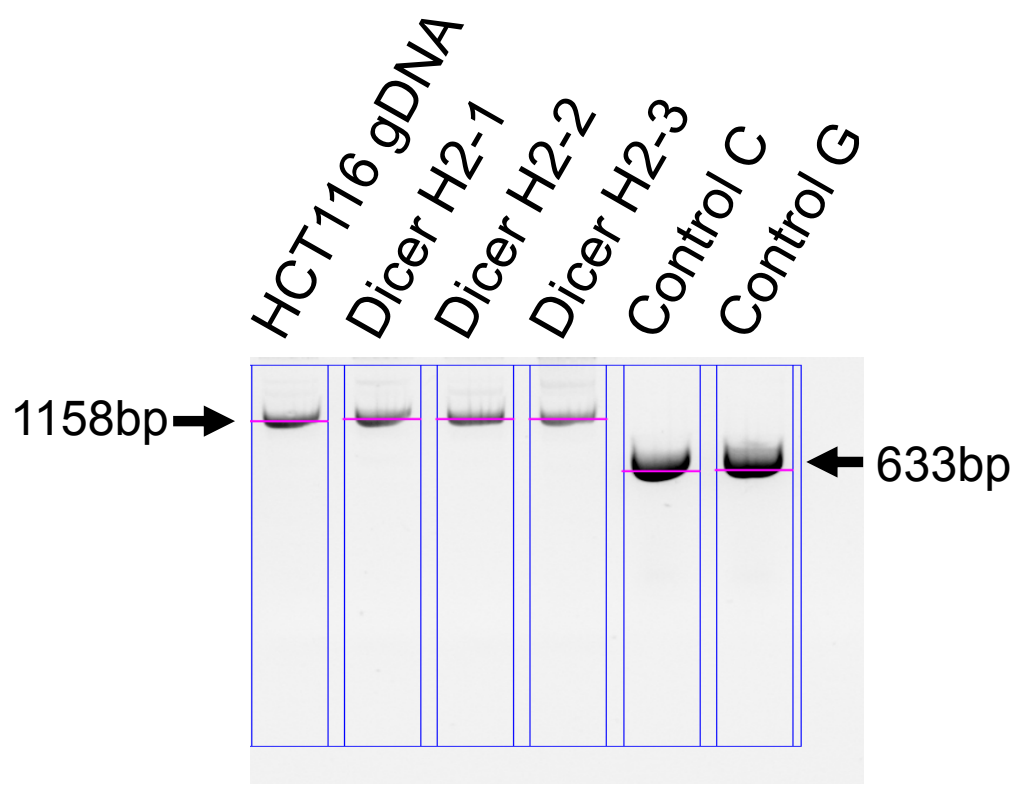

B

\section{CONTROL $\mathrm{C} / \mathrm{G}: \mathbf{6 6 3 \mathrm { bp } = 4 1 6 + 2 1 7}$}

ACACCTGATCAAGCCTGTTCATTTGATTACCAGAGAGACTGTCATGATCCACATGGAGGGAAGGACATGTGT GTTGCTGGAGCCATTCAAAATTTCACATCTCAGCTTGGCCATTTCCGCCATGGAACATCTGATCGTCGATAT AATATGACAGAGGCTTTGTTATTTTTATCCCACTTCATGGGAGATATTCATCAGCCTATGCATGTTGGATTT ACAAGTGATATGGGAGGAACAGTATAGATTTGCGCTGGTTTCGCCACAAATCCAACCTGCACCATGTTTGG GATAGAGAGATTATTCTTACAGCTGCAGCAGATTACCATGGTAAGGATATGCACTCTCTCCTACAAGACATA CAGAGGAACTTTACAGAGGGTAGTTGGTTGCAAGATGTTGAATCCTGGAAGGAAT $\underline{\text { TGATGATATCTCTACT }}$ AGCGCCAATAAGTATGCTAAGGAGAGTATAAAACTAGCCTGTAACTGGGGTTACAAAGATGTTGAATCTGGC GAAACTCTGTCAGATAAATACTTCAACACAAGAATGCCAATTGTCATGAAACGGATAGCTCAGGGTGGAATC CGTTTATCCATGATTTTGAACCGAGTTCTTGGAAGCTCCGCAGATCATTCTTTGGCG 
A

- DI_S

$\square$ DI_AS

AS preferency DsiRNA I

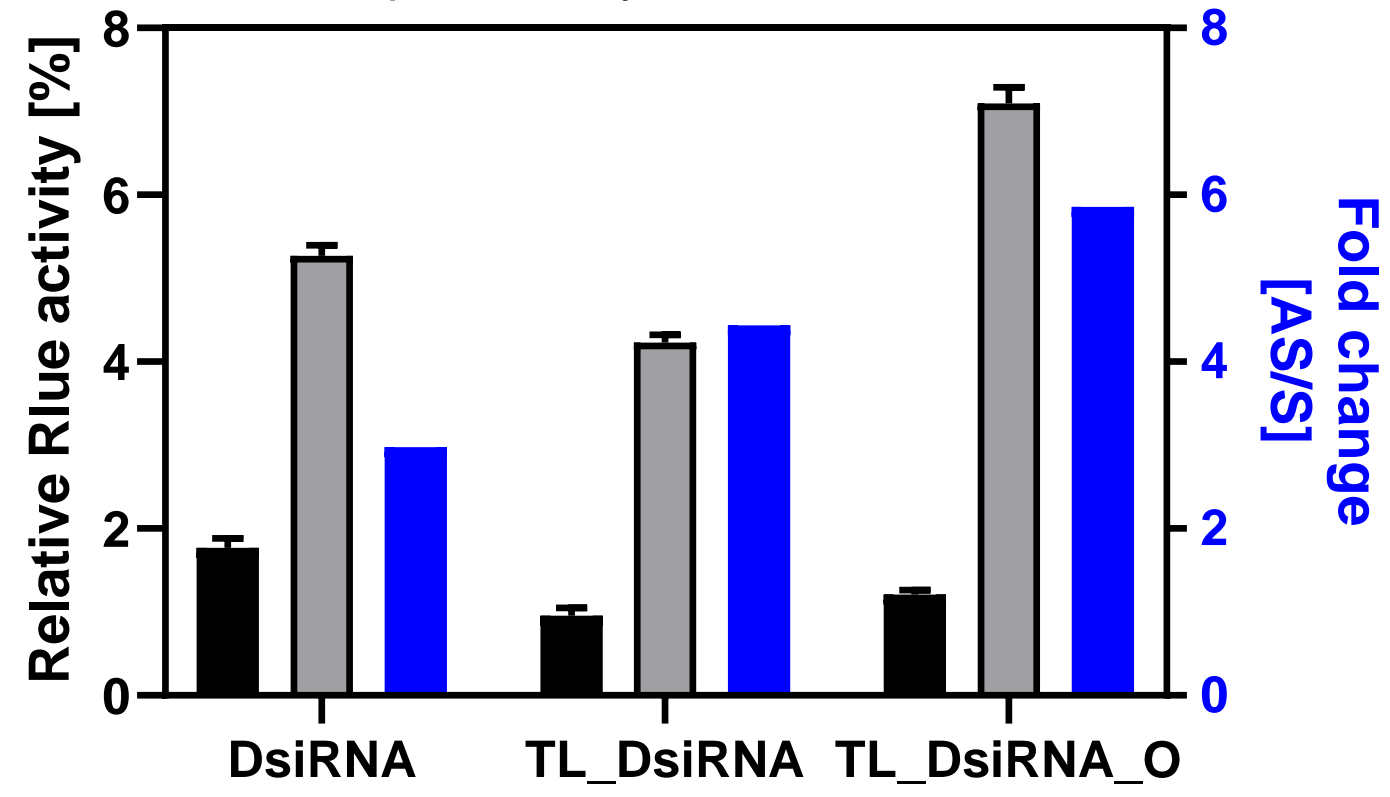

B

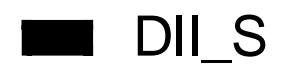

$\square$ DII_AS

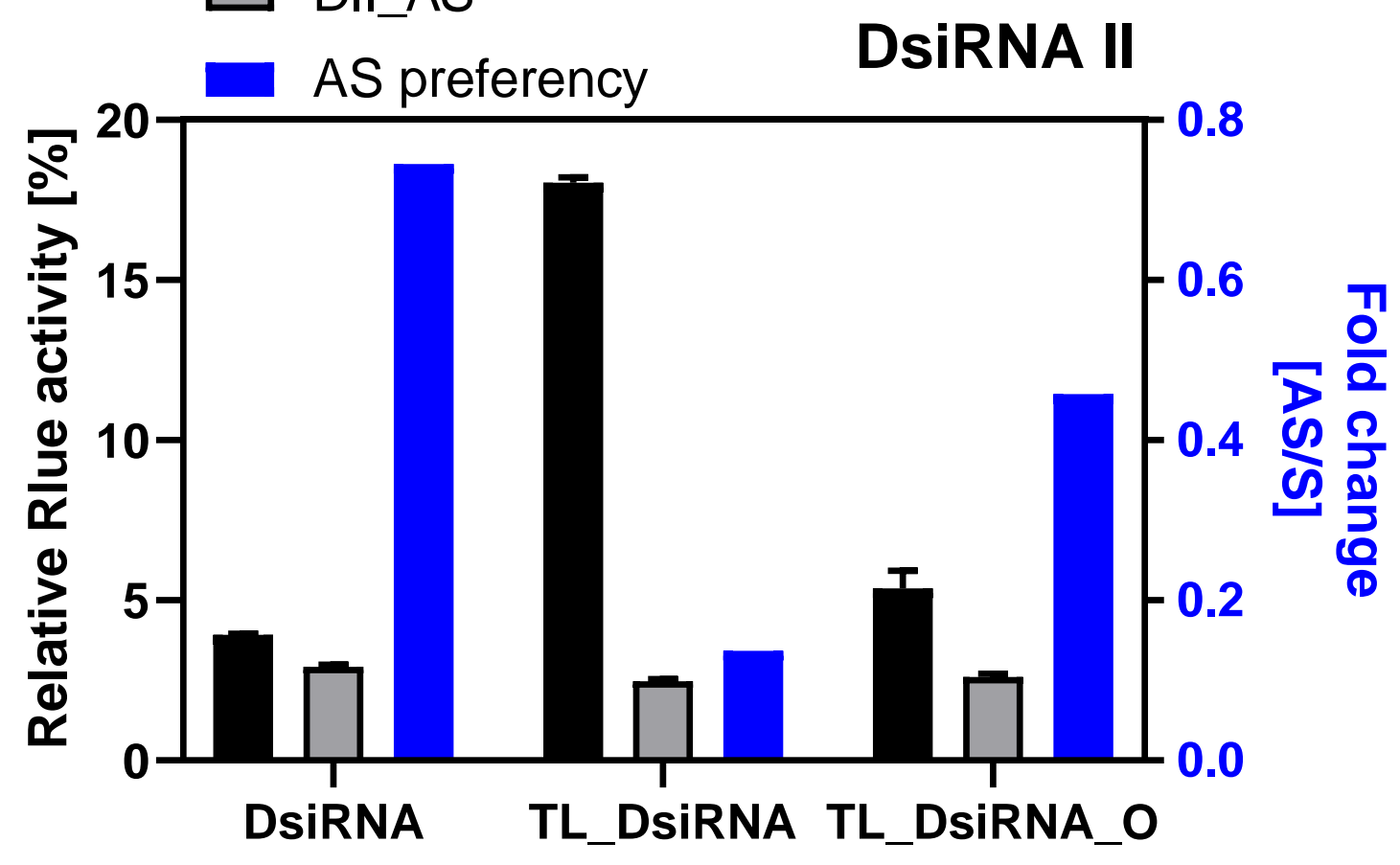

Song et. al. Supplementary Figure 2 